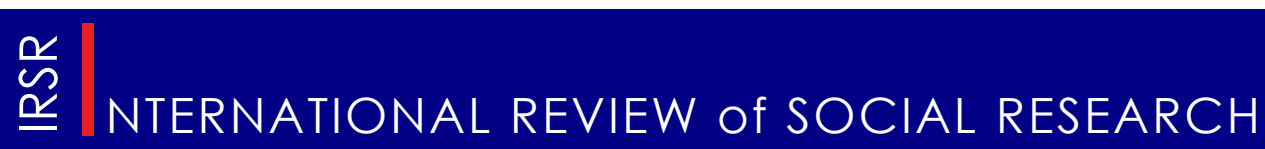

\title{
Apples, Quality Signs and Trademarks for Local Products
}

\author{
Anda BECUT * \\ Center for Research on Culture, Bucharest
}

\begin{abstract}
The interest for food quality is one result of the changes in consumption practices and of the food crisis that generated customers' distrust. The latter became more and more interested not only in the food's properties, but also in the conditions of its production (hygienic security, fairly paid labor and proper work conditions) and distribution (product's origin, traceability control). In this context, the attention has moved to food production and distribution and to economic practices, focusing on the economic and social dimension of the food system. In this article, I have analyzed how food quality is built, both culturally (through signs such as authenticity, hygiene and ecology) and politically (through official labels such as protected designation of origin - PDO, protected geographical indication - PGI). I also analyze how Voineşti apples achieved commercial notoriety as an example of the food products known in the Francophone literature as 'terroir' products, in order to highlight specific practices of quality performing and different types of quality discourses related to them. I touch upon the economy of quality, the quality standards, signs and marks, the European and Romanian legislation regarding local products, the process of quality certification and the local products as quality products.
\end{abstract}

Keywords: food, food quality, local products, organic products, trademarks

\section{Contemporary approaches of food quality}

Anthropological studies have recently paid increasing attention to food issues and their symbols. (Douglas, 2008; Goody, 1996; Mintz \& Du Bois, 2002) Food has never been only food, and its significance is not only related to physical survival, but also to social relations. Fischler considered food as essential for our identity 'the action in which we send a food across the frontier between the world and the self, between 'outside' and 'inside' our body' (Fischler, 1980). Food concern started from the moment it was used as a sign for class, gender, status, income,

•email: anda.becut@culturadata.ro. 
age and ethnicity.

The competition in the food system became more and more aggressive in the last years and the smaller price strategy is no longer the only option for attracting clients. In this context the 'best' and the safer food product strategy is a good alternative. Fears and anxieties of the post-modern society and the worship of the body as a new religion, the development of ecology and environment science are the roots for the public concern for food quality and safety. Globalization resulted in the increase of the value and number of food products on international level and in an increased variety of the food produced, sold and consumed on local level. This way the differentiation of food products began - through private labels, special services - and the retailers began to impose a series of private standards to their suppliers. These private standards were meant to improve consumers' attitudes towards food in an age of anxiety. As Iain Wilkinson stated 'It is now a matter of sociological common sense to identify ourselves as living through a period of acute insecurity and high anxiety' (Wilkinson, 2010: 153).

However, what is the meaning of quality in the food system? There are two theoretical approaches on food quality. According to the first one, the quality has an objective dimension, assigning product's characteristics that allow its identification (Sylvestre, 2002: 180). In this sense, quality can be measurable and controllable with standard instruments and aims at highlighting certain technological criteria for quality recognition. The second approach on quality states a high level of consumer's satisfaction.
A quality product is considered an exceptional, rare, superior, 'deluxe' and 'festive' product (Ibid., 280). In this approach, the notion of quality is associated with the notions of rarity, individuality and smallscale production. In Europe, quality certification policies, particularly designations of origin and labels for traditional and organic products have the roots in the second approach. The essential device of the quality policy is the legal system which legalizes the exclusive reservation of products' origin use in order to point out those specific products guaranteed as 'original', 'typical', 'authentic', 'of superior quality', or even 'natural' (Ibid.: 185).

The stake of the quality policy is drawing consumers' attention by presenting product's or production's characteristics as being trustworthy. This dimension of credibility is essential in order for labels to become a value source for the actors of the production and distribution networks, as well as for the consumers. Products' quality is not an abstract concept; it is either built by the economic actors through voluntary agreements (product specification) or through public policy decisions (e.g. minimum quality standard) (Prigent-Simonin \& HéraultFournier, 2005: 4). The definition of quality must be related to the economic transactions, which raise the problem of warranty and control methods. Therefore, there is an 'economy' of quality signs, considered as a sort of 'contract' between the producer and the consumers (Ibid.: 5). This contract must define the information that will be provided to consumers and also the ways of the agreement's warranty. 
From this viewpoint, there are two quality signs used in the food sector: the brands (industrial or retailers') and the trademarks (official quality signs). The brand involves an informal agreement with the consumers that do not necessarily know the product specification, but, by repeated purchase, they anticipate the products' quality (Ibid.: 6.).

The main way to guarantee the product's quality relies on the economic value of the product's reputation, which, if maintained, leads to avoiding clients' deceit techniques. National or European official quality signs rely on a different type of contract. The final quality and its related product specification are the result of a collective agreement between different members of the food production and distribution network. Quality certification essentially comes from an endorsement from a third public party because the public power credibility is at stake for certifying that particular product specification (Ibid.: 7). In certain cases, private standards are used to compensate for the lack of public standards or they respond to the market demand for food security.

In the following lines, I shall analyze how quality is built and how it is highlighted in the Romanian food system. Which are the legal provisions and trademarks (official quality signs)? Which are the conditions for obtaining the quality certification? Which are the criteria for evaluating a product as a quality product and how did the Voineşti apples become 'terroir' products? These research questions started from the display of the origin village name on the price label and of the various apples' characteristics : 'The beautiful from Voineşti', 'original
Jonathan of Voinești', 'Florina (a girl's name) of Voineşti, sweet and perfumed', 'Jonathan original 100\%', 'Organic apples', etc. My research took place in Bucharest, in the Obor Market in November 2003, and in the Voineşti village in February 2005 and September 2009. The main research methods were the semi-structured interview, participant observation and Photo-Elicitation. Interviews were used mainly in the Voinești community and their purpose was to find out what the Voineşti-specific practices of apple production and distribution were, what the customers' perceptions were and what reason there was for using the 'Voinești apples' designation. In the Obor Market, mainly participant observation and photo-elicitation were used, because of the sensitive subject regarding the apples' origin in the context of a conflict between producers and middlemen and of the rumour regarding the marketplace closure.

\section{Official quality marks for agricultural and food products}

The objective of the system of registration and protection of the intellectual property rights for food products (local, organic, traditional or designation of origin products) is to protect both producers and consumers from 'fake' products and to provide a set of authentication and quality control regulations. In the following pages, I shall shortly synthesize the main legal aspects regarding the designation of origin and geographical indication protection. In addition, it is worth mentioning some of the legal provisions regarding traditional and 
organic products, from the viewpoint of their association with 'terroir' products.

\section{$P D O$ and $P G I$}

The international framework for the designation of origin and geographical indication protection includes: The Paris Convention for Industrial Property Protection, March 20, 1883, The Madrid Agreement for the Repression of False or Deceptive Indications of Source on Goods, April 14, 1891, The Lisbon Agreement for the Protection of Designations of Origin and their International Registration, October 31, 1958, The Agreement on Trade-Related Aspects of Intellectual Property Rights (TRIPS Agreement, 1994).

In order for a product to be protected in the European Union, it must be first acknowledged in the member state where it comes from and then at the European Community level it must be included in an index of designations of origin or protected geographical indications. The definitions for PDO and PGI are the same: the name of a region, a specific place or, in some exceptional cases, a country, used to describe an agricultural product or a food product' (Council Regulation, EC, No 510/2006).

The difference consists in the

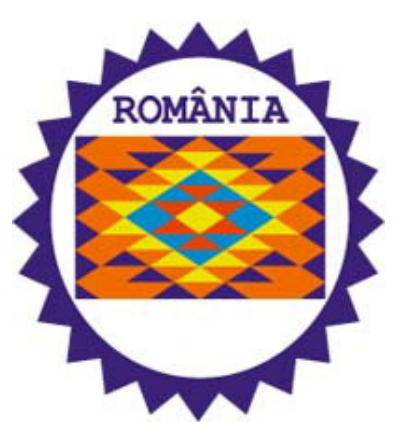

Figure 1. Country label

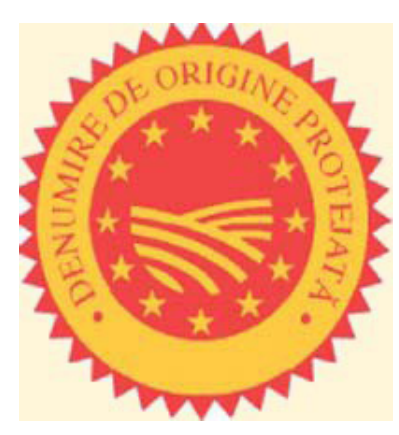

Figure 1. PDO label

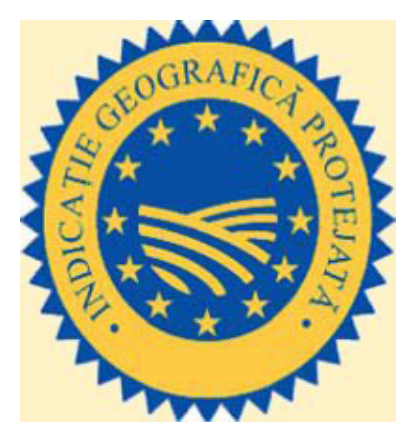

Figure 1. Country label

certification conditions for the product. In order to obtain a certification, a product must be from a region, a specific place or country and its preparation and processing have to take place in that confined geographical area. For PGI products, the specific condition is to have a specific quality, reputation and other characteristics attributable to that geographical area, while for the PDO products the specific condition is to have a quality and characteristics that are essentially and exclusively due to a particular geographical environment with its inherent natural and human factors (Council Regulation, EC, No 510/2006).

In order to obtain designation of origin and geographical indication protection, the applicants must be organized as a group of producers and must represent the local community in this collective action. The group is the only interlocutor with The National Office for Romanian Traditional and Organic Products, the local institution appointed to run the certification process. After certification, the products will receive a visual identity on which will be sold with all the rights protected. This visual identity is known as the blue label as shown in the images bellow: 
The authentication and quality control regulations also include other three types of product identification: traditional products, guaranteed traditional specialties and organic products.

\section{Guaranteed traditional specialties}

Article 2 of the Council Regulation, EC, No 509/2006 states that 'traditional means proven usage in the Community market for a time period showing transmission between generations; this period should be that generally ascribed to one human generation, at least 25 years' and 'specific character means the characteristic or set of characteristics which distinguishes an agricultural product or a food product clearly from other similar products or food products of the same category'. As in the case of PDO and PGI certification for guaranteed traditional specialties, the group of producers is the only entity that may apply for certification.

\section{Organic Products}

Council Regulation, EC, No. 1254/2008 states: 'organic plant production involves varied cultivation practices and limited use of fertilizers and conditioners of low solubility, therefore these practices should be specified. In particular, conditions for the use of certain non-synthetic products should be laid down' and ,the holistic approach of organic farming requires a livestock production related to the land, where the produced manure is used to nourish the crop production'. National and EU laws establish strict regulations for the use of fertilizers and plant protection procedures against pests and diseases, against environment pollution and specify the prohibition of genetically modified organisms (GMO) in certified organic productions. It is worth mentioning that in Romania the debate regarding GMO production has not the same dimensions like in other European countries, having been triggered in mass media only following NGO punctual actions and some initiatives of the Romanian Ministry of Agriculture.

Local products, quality food products Local food products have been the subject of many studies in South Europe both from ethnologic and marketing viewpoints. The idea of local products is related with the development of the concept of territorialized economy, in opposition to the globalized economy. In recent years, we have witnessed the change from a standardized economy, based on globally valid regulations, to a territorial economy, a proximity economy, characterized on localized agro-food systems, territory becoming a central value. (Amilien, 2005: 12) Designation of origin products (DOP) are known in France as 'terroir' products because of the notoriety achieved in time by the French food products, by association with 'à la français' lifestyle.

As a paradox, these products specific to a territorialized economy became known on account of the globalization, tourism and marketing practices. However, products with geographical origins are relevant only within the collective representation about that place and its associated features.

The quality of 'terroir' products is determined by three aspects: territorial 
origin, traditional value and organic aspect. At origin, the expression 'terroir' is specific to France and is quasiintroduced in other countries, including the South Europe. It was certified at the beginning of 13th century and it was equivalent with the land or territory. (Bérard \& P Marchenay, 1995: 3) By the 18th century, it kept its meaning of territory, firstly considered because of the agricultural aspect, especially in the case of the soils for wine culture. (Ibid.: 5) At the middle of the 16th century it entered the expression 'gout de terroir' related with wine and then it applied by metaphor to people who have qualities and flaws specific to a particular country (Ibid.).

Today 'terroir' has become a familiar category in French society and consumers use this term for products they spontaneously associate with the idea of a geographical origin, a quality and a taste a priori deemed authentic and traditional (Bérard et al., 2005: 5). The type of system in which a product to be marketed is made is important from the product's quality and quality warranty viewpoint, the more necessary the more the product is alienated from the producer and production place. Local food product is typically related to an identifiable location through geography, knowledge and tradition. French authors consider 'terroir' products as related to origin concepts (geography, climate), culture (time and tradition) and 'savoir-faire'. 'Savoirfaire', in this context, includes both traditional ancient knowledge and the new, innovative one (Amilien, Fort \& Ferras, 2007: 8).

\section{Voineşti apples, 'terroir' products}

Although it is not the purpose of this paper to present an in-depth analysis of property relations, the status of producers and their distribution network, for the purpose of this article though, it is worth mentioning that the main occupation in the Voineşti community is agriculture ( $40 \%$ of the village population) Fruit growing is the main activity, with a production in 2002 of 9.837 tones on 295 hectares. The main fields are small and medium plantations (between half a hectare and 10 hectares). If during the 90 's most of the villagers sold the apples in urban marketplaces, in 2003 only $10 \%$ went to marketplaces to sell their products.

I shall consider Voineşti apples as 'terroir' products, a category of fruit with a social history that covers three periods (the communist period, the transition period and the UE integration period) and I shall present reasons for this statement. The process of achieving local prestige is specific to Voineşti apples before the establishment of the Station for FruitGrowing Research and Production (1950) and is related with a subsistence peasant society where the main reason for growing apples was respect for the land and the desire of the local people for prestige in their community. This local prestige derived from working the land and from the harvest, reasons for which the 'good householder' was proud within the community. The main reason for apple growing was the household subsistence. Therefore, at this stage we cannot speak about trade notoriety but only about a local prestige. The products' quality is a concept introduced later and is particularly related to the process of apples' commodification and to the change from subsistence to market 
economy. Rural producers arrived in Bucharest marketplaces in the 1960s.

In the second stage of the Voineşti apples' social history, their prestige is 'confiscated' by the new sorts of apples produced in the Station for Fruit-Growing Research labs. Thus, the 'Voineşti' designation is officially acknowledged but it is associated to a single hybrid product and not to a category of apples, it is the result of the science development and not of the local community tradition. The apples' local prestige is replaced this way with the 'scientific reputation'. From a consumption viewpoint, I shall consider this type of notoriety as characteristic to a stage of Voinești apples' anonymization because of the anonymity of the industrial production process. Voineşti apples collected and distributed by 'Coletărie' (a centralized institution that collected, transported and distributed the apples) and 'Aprozare' (a network of fruits and vegetables state shops) become 'unidentified food objects' (Bétry, 2003), losing any contact with territory, relation which is only kept for 'scientific reputation'.

In the third stage, the Voinești apples achieve commercial awareness by the mark of their origin on the price label, associated with their acknowledgement by consumers not only as products with prestige but also as 'prestige products'. The labeling and symbol-assigning of the origin territory began in 1990 . Commercial awareness is the result of the commodification process and has the roots in the local prestige, as well as in the 'scientific reputation'.

In the context of a low competition with other fruit-growing production regions at national level, the Voineşti apples achieved visibility in the Bucharest marketplaces through their producers-vendors. Their visual and taste characteristics and the sellers' ability to attract customers brought them the prestige of local quality products. During the 1990's, during the transition period, the opening of the borders was concomitant with the open admission of imported food products that generated an unexpected competition for local products, including those in the fruit sector. The blow was even bigger with the obstruction of any globalization action during the national-socialist regime. Imported products rapidly seduced Romanian consumers for whom any new product was attractive. Thus, the need to differentiate between food products appeared, materialized at the beginning through the distinction between Romanian and foreign products and then through distinction between different local production regions.

This is the beginning of displaying at sale the territorial origin along with the price of the product. In the case of the Voineşti apples the differentiation from the other products did not need particular marketing techniques, because they were known by consumers from the socialist period. Another reason for displaying the products' origin is related to the competition in the urban marketplaces for the better stalls, which generated a competition between sellers who used their origin in order not to be perceived by costumers as middlemen.

The practice of displaying the territorial origin at sale is more interesting as it reflects the social and economic changes during transition 
period. Thus, the promotion of the territorial origin of the products reflects realities such as free trade, the competition between national and imported products, the changes in consumption practices, the decrease of life standards and the reconfiguration of the food system through the disappearance of the old actors ('Coletăria', 'Aprozarul', food processing factories) and the raise of new actors (middlemen, carriers, import-export companies, big retailers, wholesale commercial spaces).

These economic and social changes determine a high competition in the urban marketplaces that become power and control spaces, desired territories for the access to profit opportunities. In the context of the pauperization of an urban social category as a consequence of the deindustrialization and of the economic turbulences during transition period, the urban market, previously dominated by the rural producers, becomes more and more attractive for other social categories that enter the food system as middlemen. This phenomenon marks the gradual exclusion (forced or voluntary) of the most of the Voineşti village producers from the urban commercial environment, but also the adjustment of those who are still in the market to the new competition situation. The promotion of territorial origin is, in this context, an innovative act meant to mark the difference and the quality of the sold products and of the people that produce and sell them, too. That is because resorting to territorial origin does not only promote the taste qualities of the product but also the qualities of the rural space and of the people of that place. The promotion of Voineşti apples as 'terroir' products involves highlighting the local tradition, the 'savoir-faire' of the producers and sellers from the Voineşti village, as well as the Romanian research results. And all these in opposition to the new imported products and the new actors in the urban market.

The new realities are marked on one side by the overestimation discourse of the Romanian products' and local producers' quality and on the other side by the underestimation of the middlemen and imported products' quality. Thus, the imported products are considered tasteless by the Voinești producers and the middlemen are cursed and blamed for all the difficulties that producers have to confront in the transition period. The main reason for the conflict between Voineşti producers-vendors and the middlemen is the abusive use of the name 'Voineşti' for imported apples. On the other hand, the use of this name for the apples bought from Voineşti disadvantages some local producers (those who sell their merchandise in the urban marketplace) but favors the others (those who sell their merchandise directly from their household)

In the 90's, West-European products were attractive in the same way as the 'terroir' South-East European products are today for tourists from western countries: they represented the 'taste of the west'. The East-Europeans wanted to know West Europe culturally, through the 'ingestion' (Jousse, 1974) of its defining products. This period can be characterized by 'not only food but also symbolic bulimia' (Mihailescu \& Iancu, 2009). If the East is characterized especially by exotic tastes and smells 
the West is defined by visual aesthetics. If, for Romanian customers, western products were interesting shortly after the fall of communism, as an effect of the availability of the 'forbidden fruit', in time, the enthusiasm for foreign products decreased significantly in favor of the local products. And the rightful owners of the local products were the local producers who tried to survive in a market in the context of an unfair competition with middlemen. Voineşti apples were used in this competition as an identity and differentiation element, both at national and local level. They were perceived by consumers as an expression of national quality, and a local pride element as well, becoming the symbol of diversity promotion, as opposed to supermarket product levelling.

The taste quality of a meal is a celebration, it means assuming the eating pleasure in order to highlight accordingly the quality of the day in itself (Le Breton, 2009: 57). Likewise, the opposite applies: during holidays, the taste quality of a meal blissfully accomplishes the moment. 'Terroir' products are different from the other types of products through their relation with time, not only through that with space. If the other products are associated with the 'profane time', 'terroir' products mark 'the sacred time' or 'the celebration time'. Voineşti apples are an example of 'terroir' products preferred by the costumers especially during holidays.

The reputation of the Voineşti apples and their status as 'terroir' products or as prestige products are highlighted not only through their acknowledgement as natural products, but also through the haute cuisine experts' recommendations, for their special taste and for the diversity of ways in which they can be prepared. Thus, in the article 'The Golden Chef of Bucharest' by Catalina Matei, in the Romanian Modern Gastronomy Contest, among the finalists there was the representative of Grand Hotel Continental, who prepared 'Voineştiapple pie' for dessert (Matei, 2009).

I have identified three types of discourses regarding the quality of the Voineşti apples: the identity discourse, the health discourse (including hygienic and organic aspects) and the esthetic discourse. The identity discourse associates the idea of quality with the origin territory (a region with fruit-growing tradition) and with the qualities of the people that produce Voineşti apples (savoir-faire, good householders). The health discourse associates the Voineşti apples with organic characteristics and natural products. Finally, the esthetic discourse promotes the Voineşti apples' look, 'beautiful' becoming a name for a sort of apple but also a quality indicator. It is worth mentioning that every type of discourse corresponds to a specific quality sign, such as it was culturally built and perceived by the consumers. In the following pages I shall illustrate these three types of discourses and the manner of building quality signs.

\section{Authenticity as a sign of food quality Recently, the food consumption dynamic has strongly integrated different types of products, more or less natural. The identification and representation of a production space may show a consumer the authenticity of the product. These elements and}


others from the production sectors lead to the development of legal labelling practices, which aim in different ways at granting the consumer a warranty and the authentication of a relation between a product and its geographical space of origin, in order to protect that product from possible counterfeits. Thus, local food products seem to have a greater value as indicators for local and traditional cultural identity than as marketing labels (Amilien, Torjusen \& Vittersø, 2007: 5).

Although the territorial origin is a central collective argument, tradition is the main structural framework, providing a historical existence to the product and a 'terroir' dimension, which thus generates credibility in the local values. In the case of 'terroir' products, the authenticity is paradoxically maintained due to innovation, commodification and marketization (Ibid.: 8). Thus, for 'terroir' products the innovation is accepted only when the product continues to be important. In the concept of 'terroir' products the place does not pre-exist his inhabitants, on the contrary, it is the result of an 'invention'. The issue of the authenticity comes from the confrontation between the desire of preserving specificity and the generalization of the industrial production forms. In the food sector, the historic conditions of authenticity demand are related to the mechanization of the agriculture, the food industry development and the popularization of the food risks that created a bigger and bigger rupture between consumption and natural environment (BonnainDulon \& Brochot, 2004, 10).

Authenticity does not exist in itself but is a social and commercial construction that is invoked according to the personality given to the product. This responds strictly to the customer's demand, allowing the consumer to approach a place, an ideal of traditional life, to find out about a history where authenticity is combined with quality (Ibid.: 11). By labelling, authenticity is promoted as a synonym for safety. Local quality is combined with organic quality and the products are perceived as safe. From the quality viewpoint, the local value is more important than the traditional one. The territory of origin means the origin from our territory, which we know and feel secure about (Idem.). 'Terroir' products create a space of security, a familiar universe, an idyllic territory which could not be desecrated by doubts and insecurity.

Food products have an essential role in the search for personal identity in the process of people's and societies' 'individualization'. This confirms Braudel's assertion 'wine is not just wine' (Muchnik, Biénabe \& Cerdan, 2005: 5). In a changing world, food products play an important role for people and society in the reconstruction of their identity references. Food accomplishes other functions, too, not only that of satisfying physiological needs, it triggers emotions and refers to shared values and landmarks, therefore having also the function to fulfil socialization needs (Prigent-Simonin \& Hérault-Fournier, 2005: 7). Hence consumers will seek for such products with strong identity, highlighted either by emphasized valorisation of wellknown products or by revitalization of particular traditions or traditional products. Symbolic values associated with food products are highly related to the consumers' readiness to pay the price for those products (Idem.). 
The identity 'sells' very well as long as the authentic products consumption provides a certain meaning to people who are more than simple consumers, they are identity and value 'searchers'. The selling is not only an economic action, but also an action of creation and reconstruction of the social networks where food acts as mediator (Muchnik, Biénabe \& Cerdan, 2005: $5)$. The challenge is to redefine and provide symbolic value to these products and to combine the hygienic standards with the nutritional ones. Sometimes authenticity is mistaken for product quality.

In the context of a so-called monopoly of the Voineşti apples in Bucharest marketplaces before the 90's, the uncertainty regarding the Voineşti apples' authenticity is not relevant because they were perceived by consumers as local products. Later, in the context of an increased competition with imported fruits, they began to be perceived more and more as 'terroir' products, characterized by a tradition and an origin territory. The authenticity of the Voineşti apples began to be questionable in the context of the entry in the market of the imported fruits and of the middlemen. The disappearance of the direct relation between apples and their producers-vendors generated a process of persuading the customers as far as the authenticity of the Voineşti apples' region authenticity was concerned.

An important element in this process was the promotion of the new sorts of Voineşti apples, unique in the Romanian market thanks to their taste and esthetic characteristics. These new sorts of apples gradually began to be acknowledged as the real
Voinești apples, whatever the network of distribution. They have been associated with the tradition of fruitgrowing research and production in a familiar space for Bucharest consumers through their knowledge of the region or through the knowledge of their characteristics and of the producers from the Voineşti village.

In the process of persuading the customers about the region authenticity of the Voineşti apples, displaying their origin on the price label played an important role. This practice was used with a view to dismissing any uncertainty regarding the fruit quality and reminding the customers about the specificity of the products. The difference between Voineşti apples and any other apple from the market was their identity and their reputation built by resorting to a space of tradition and origin. Another authentication practice consisted in offering clients a piece of apple to taste in order to dismiss any suspicion regarding the merchandise quality.

\section{Hygiene as a sign of food quality}

Product's quality is the consequence of the interaction between actors, entities and symbols involved in production, distribution and consumption. This is why the products' quality is never intrinsic but is defined by 'relation to something' (Prigent-Simonin \& Hérault-Fournier, 2005: 7). The quality is a way to assure that the product is safe for consumers or it refers to "the capacity of a product/service to satisfy a set of user expectations' (Idem.). Cazes-Valette states that products' quality is nutritional (assuring nutritional equilibrium), functional 
(if they are proper for selling, transportation or preparation), hygienic (do not contain harmful or toxic substances), organoleptic (if they are good or bad to taste), social (assure the identification of the group belonging feeling), symbolic (they are part of the eatable list products culturally defined), humanistic (respect the environment and fair trade) (Ibid.: 9).

Not always the products comply with all these requests in order to be considered as quality ones, moreover, in some situations there is a tension between these quality dimensions depending on what is important in that situation. As far as the hygiene is concerned, what assures safety and trust in products also determines their perception as food quality products. In some situations, complying with the hygienic rules opposes the product's traditional characteristics or the trade context. I am referring especially to traditional urban marketplaces, which were the spaces of products' quality contesting from the point of view of hygienic rules compliance. These urban marketplaces are one of the few places where producers come in direct contact with consumers and, in this respect, they are important spaces of knowledge and experience exchange.

On one hand, traditional urban marketplaces support the local food production and on the other hand they help the sharing of the local knowledge and food traditions. In the past, marketplaces were usually associated with diseases and uncleanliness, generating distrust, which food policies tried to eliminate. An example is the European Union legislation regarding food safety and hygiene (Black, 2005: 10). However, there are cultural differences regarding hygienic risks. 'Hygienic norms accompany the globalization of the economy through the different sanitary regulations that States today must comply with. They [regulations] also cross cultural registers because of the place that certain countries give to hygiene; this changes the way in which inhabitants perceive food and the role they grant it. Even inside a culturally homogeneous situation there is still the question of the representation of risk' (Idem.).

The concept of hygiene is changing as result of the new consumption habits, especially consumption practices in the hypermarkets that give a great importance to hygiene. In Romania, some of the consumers avoid traditional marketplaces for reasons of uncleanliness and prefer hypermarkets for reasons of superior hygienic conditions. Therefore, the concept of hygiene becomes a power and control instrument in the public space, being a strong argument for the new urban development policies that restructure public space. In this context can be interpreted the public debate generated by the project of Obor agro-food traditional marketplace replacement with a 'modern', 'hygienic' space, like the space of a hypermarket. These development projects result not only in the 'modernization' of trade infrastructure, but also generate profound changes in the agro-food system, too, through reconfigurations of the distribution networks and of the actors involved in trade process. They affect equally the sellers' and near inhabitants' lives and change consumption habits and lifestyles.

This is due to the fact that hygienic regulations were created in such a 
manner as to favor the food industry and big retailers, leaving few alternatives for traditional methods of food production and distribution (Ibid., 11). Another example is the European Union legislation regarding food products packing that include hygienic standards. Voineşti apples producers could not comply with these standards, lacking high technology of sorting, washing and packaging. Therefore, the concept about agro-food products quality (including hygiene) reflects the economic, political and social changes of a society. Therefore, trust plays an important role in quality setting and it is very interesting to analyze how quality derives from the direct relation between producer and consumer and contributes to the conceptualization of food products quality. In the case of 'terroir' products, the tension between hygienic aspects and those related to identity and symbol is greater in the products' quality certification.

\section{Organic as a sign of food quality}

In the sustainable development policies, nature became environment. Although it is an old science, ecology began to be used in the 60's and 70's as a power instrument, becoming slowly an ideology with more and more followers. Marc Mormont states that ecology has three different interconnected dimensions. At its origin, ecology was a science that reformulated the object of biology, being interested particularly in human intervention consequences on the natural environment (Mormont, 2009: 144). Scientific ecology, named by the author eco1, has a critical or reflexive dimension because it highlights the harmful effects of the general progress on the environment. This alarming state is the object of the ecological policy, named eco 2 by the author, which has the objective of devising a social critique of modernization, aiming at environment policies integration within public policies (Idem.). The third type of ecology (eco3) is focused on the overall relations between socioeconomic systems and biophysics systems.

In the agro-food system, the ecology took the shape of the ecological policies (eco3). This dimension involves an environment 'friendly' type of agriculture, even though the negative effects of agriculture are not as serious as those of the industrialization. If in the 50's and 70's, the development approach included agricultural mechanization and industrialization required by a certain type of modern agriculture, opposed to traditional rudimentary agriculture, exposed to climatic risks, nowadays another type of agriculture is promoted, an agriculture that is trying to combine the use of state-of-the-art technical equipment with specific traditional agricultural practices, less intervening in the natural environment. An interesting aspect of the new agro-food approach is the fact that the organic is a priority now, but this organic is defined by the European Union's common legislation.

Consequently, the organic is a cultural construct and, like any cultural construct, it has a dynamics related to general dominant approaches in a certain period. This dynamics is influenced particularly by the tensions between the different viewpoints on the negative effects of human 
intervention on the environment. An example is the use of water resources required to produce good apples harvest, even though chemical substances or fertilizers were not used for those apples. Surely, the use of natural fertilizers is an organic practice, but to what extent the use of water resources, of modern irrigation systems is an organic practice and to what extent it is more or less harmful to the environment is another aspect to take into account.

Here occurs the experts and public policies' role to define the technical conditions of classifying an economic practice as an organic one. At common sense level, I have noticed a relativization of the organic concept and its judgment depending on the context favorable to the interest of the moment. Nevertheless, it is certain that the tension between the requirements of a superior agro-food production or the greater and greater claims of the market and the introduction of less harmful environment practices are concomitant with the food system's dynamics and will take the shape of the dominant organic approach specific to that particular moment.

The green trend entered our country in a compulsory manner, along with the compliance with the European regulations and through mass-media awareness campaigns on the negative effects of the industrialized production. Acknowledged and authenticated Bio products, the food expression of the organic trend, were known in the beginning by Romanian consumers in the West-European space and for several years they have been distributed in the Romanian market, too. As far as the organic Romanian food production is concerned, it is predominant in the individual, household type of system, being acknowledged as organic only after a complicated system of authentication.

Bio products are a different category of acknowledged products, beneficiaries of the intellectual property rights. Even so, they are usually associated and sometimes mistaken for local products or products of geographical origin. Food products produced in a certain region are perceived as pure and secure, a possible explanation being that in the past everything was organic. Therefore, local and traditional food is automatically associated with organic food. This association is based on the consumers' logic inference that relates food products' origin production place to the proximity with nature and the lack of artificial interference. In other words, the more a product is localizable in a rural area, the more increased are its chances to be a bio, organic product. If in the case of local products this inference is true, in the case of 'terroir' products this is not always valid. In the case of geographical origin products or in the case of traditional products, organic dimension is not compulsory in the process for property rights acknowledgement. Moreover, local products, being close to the consumer and easily recognized by him, do not need 'artificial improvements' or special 'embellishments'. At producers' level there is generally an association between bio dimension and direct selling, while at consumers' level there is noticed an association between farm products and bio products, that means that for the product directly sold there is not a perception of the additive 
or chemical substances, $80 \%$ of consumers associating local products with bio products (Ibid.: 146). Instead, 'terroir' products, entering in various sales-networks had to adapt to the wild competition and to survive in the market, organic characteristics being left on a secondary position.

In the case of the Voinești apples, organic aspects have been for a long while less important for their image as quality products. Their taste qualities more than their origin - associated them with organic products in consumers' perception. However, as a result of their perception as Romanian authentic products, they were associated with organic products. This is due to the myth that Romanian organic products are 'more' organic than imported ones, legitimated by the lack of resources to purchase the chemical content that may alter the taste in favor of the products' aesthetics. In time, the Voineşti apples began to be perceived as organic apples compared to their imported competitors. Moreover, the new sorts of apples produced in the Voineşti Station for Fruit-Growing Research are more resistant to pests and diseases and can be produced in larger quantities with less chemical treatments, this way being 'more' organic. Consequently, from the organic point of view, there are differences even between the apples of the same producer, Jonathan being by far 'the least' organic sort of apple. The necessity of surviving in a market where the customers buy with their eyes and not for the taste determined the Voineşti producersvendors' orientation towards increasing productivity and apples' aesthetics, disregarding organic aspects.

To see what the consumers' perception is on the Voineşti apples as 'terroir' products, their presence in press articles, blog comments and websites is relevant. Thus, in the November issue of the Good Food magazine, entitled 'Celebrate in a Romanian Way', the Voineşti apples are present in the article '30 Reasons for Loving the Romanian Cuisine' as recommended food because of their special features. In the magazine's pages several Romanian brands are presented, with remarkable characteristics, loved by the readers and meant to be eaten at celebration moments. Thus, the Voineşti apples can be found in the select gallery of the 'terroir' products, near other prestigious Romanian brands.

In this article, the Voineşti apples are presented as organic (they are healthy), fresh, colorful, 'special Romanian' products, known as a 'brand', simple to use in different ways. In addition, the article appeals to the origin territory, an idyllic region with orchards and apples of a very good quality. The relation between the Voineşti apples and health is also highlighted in a comment posted on the Romanian vegetarians' website forum. Other comments posted on a website for bio products associate Voineşti apples with organic food and health. These examples are relevant because they highlight the consumers' perception regarding the abusive use of the designation 'of Voineşti' for imported products and raise questions about the Romanian fruit market in a globalization context. They are part of the 'bio discourse' of the apple consumption. The sensorial incorporation of 'terroir' products enrols in the approach of food as part of the local culture. David Le Breton 
states 'the world is the emanation of a body that transposes it in perceptions and senses; one cannot work without the other. The body is a semantic filter' (Le Breton, 2009: 57).

Senses like eyesight, touch, hearing and taste are specific to each culture or community. Of all these senses, the look is privileged in the urban societies, according to Simmel (Idem.). Starting from this statement, I shall consider the favoring of the other senses, particularly of the taste, smell and hearing being specific to rural societies. Taste ability is a sense through which the world is assimilated and integrated. The taste is a measure for the joy of living (Idem.). Humans feed themselves with sense before ingesting the food, and this way taste is an indicator for the joy of living. Mediated by a representation of the body as a prestige good, the relation with health becomes a functional constraint of the status (Idem.). Today health is less a biological need related to surviving and more a social demand of the status. This demand generates the obsession for a healthy and natural diet in which vegetarian practices and bio food become a lifestyle.

\section{Aesthetics as a sign of food quality}

In the case of Voineşti apples, producers' discourses send to aesthetic reasons for consumption. The aesthetics is more important than the taste, the visual being dominant in the product's choice. For this reason, the researchers from the Station for FruitGrowing Research and Production named a sort of apples 'Beautiful from Voinești'. These aesthetic discourses of the consumption are part of the economy of quality. What does, in

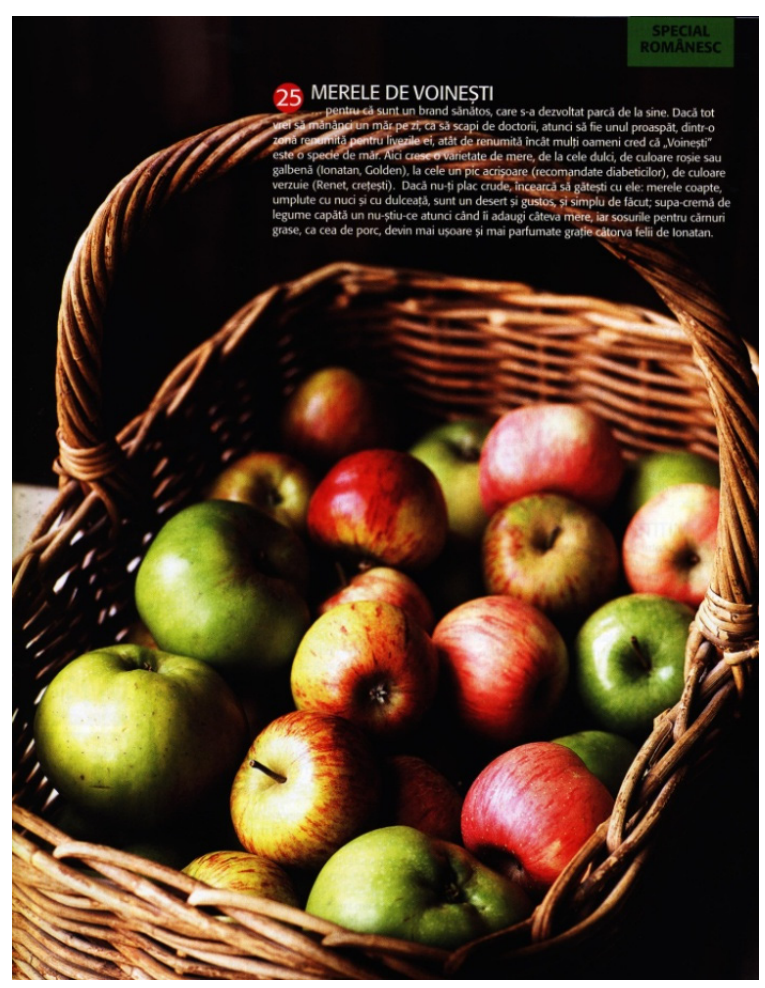

Figure 4. Good Food Magazine page 
that context, a beautiful apple mean? One apple seller from Obor Market, explained that 'It has to be big, not to have any dots, not to be deformed, it has to have a correct shape and not to have a cheap price because, if they are beautiful and they have a cheap price, they (the customers) say 'it cannot be true, there must be something wrong with these apples if they have this price' You don't know what to do. If you set a big price like that in the supermarket you do not sell any apples'. The looks of an apple matters as much as a product's label does, the higher the price on the label, the better the perception on its quality. Similarly, Voineşti apples are deemed 'terroir' products because of the prestige associated with the brand. In addition, a beautiful apple is one that has the color that the customer considers to correspond to his perception about what a 'beautiful' apple is. As psychological anthropology studies show, the symbol and perception of colors has a strong cultural basis. Through this perception, sellers from the Obor Market explain the customers' preferences for certain apples and classify customers into different cultural categories: Romanians prefer red apples, Western people prefer green apples and Chinese people prefer yellow apples.

\section{Conclusions}

In the context of the changes in consumption practices, of the food crises and of the increase in the competition between products as a consequence of the food offer diversification, quality is used to mark the specific difference. The concept of quality is built both legally (through precise norms for intellectual property rights), and politically (through institutions that manage the registration, certification and protection system), as well as culturally (through signs and symbols

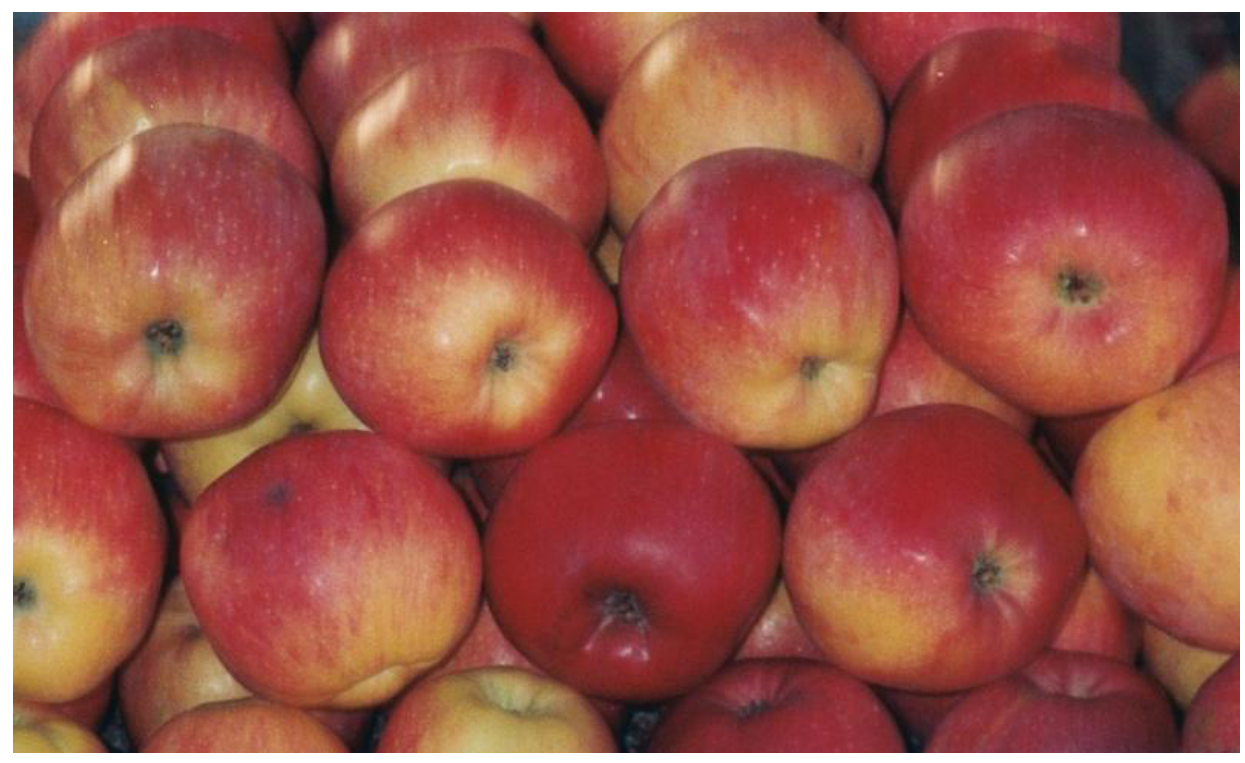

Figure 5. Voineşti apples 
meant to associate specific values to food products). I identified three types of discourses regarding the Voineşti apples' quality: the identity discourse, the health discourse (including hygienic and organic aspects) and the esthetic discourse. These three types of discourse are graded depending on each period: in the 1990s period, the aesthetic discourse was dominant, related to the supermarkets' and imported products' attraction, at the beginning of the 2000 s, identity discourse has been generalized, insisting on the opposition to imported products. Similarly, the period prior and after the Romania's EU integration (2008) was marked by the discourse about health, adapted to slow-food trends. Although the Voinesti apples are perceived by consumers as quality food products, the characteristics of the production and distribution system raise a question about their acknowledgement as protected quality products.

This paper joins the food anthropology debates through themes such as the cultural construction of quality, quality perception and specific practices for local products. Unlike other similar studies that approached the 'terroir' products, my article has highlighted different types of discourses regarding food quality in close relation to the performance of quality. Moreover, an innovative element is found in the analysis of the way the quality discourse shifts according to the production, distribution and consumption context in certain periods of time. Unlike other studies the research results highlight the fact that within certain contexts, certain quality signs are in contradiction with other quality signs, an example being the contradiction between hygiene and tradition elements. A specific element of the Voineşti apples case is that their perception as 'terroir' products does not associate them with organic products automatically, but only by reference to specific production conditions. Moreover, unlike the results of other studies, the organic aspect is relativized and nuanced by reference to the production forms in other EU countries.

\section{References}

Amilien, V., H. Torjusen \& G. Vittersø. (2005) From local food to terroir product? - Some views about Tjukkmjølk, the traditional thick sour milk from Røros, Norway. Anthropology of food, 4:1-42, retrievd from http://aof.revues.org/ index 211.html, February 10, 2010.

Amilien, V., F. Fort \& N. Ferras. (2007) Hyper-real territories and urban markets: changing conventions for local food - case studies from France and Norway'. Anthropology of food, 2: 1-30, retrievd from http://aof.revues.org/index446.html, February 10, 2010.

Bérard, L. \& P. Marchenay. (1995) Lieux, temps et preuves. La construction sociale de produits de terroir. Terrain, 24: 153-164, retrievd from http://terrain.revues. 
org/3128, February 10, 2010.

Bérard, L., M. Cegarra, M. Djama, S. Louafi, P. Marchenay, B. Roussel, F.

Verdeaux. (2005) Savoirs et savoir-faire naturalistes locaux : l'originalité française. Vertigo, 6 (1):1-12, retrievd from http://vertigo.revues.org/2887, February 10, 2010. Bétry, N. (2003) La Patrimonialisation des Fêtes, des Foires et des Marchés Classés « Sites Remarquables du Goût » ou la Mise en Valeur des Territoires par les Productions Locales. Ruralia 12/13:1-9, retrievd from http://ruralia.revues.org/346, February 10, 2010.

Black, R. E. (2005) The Porta Palazzo farmers' market: local food, regulations and changing traditions. Anthropology of food, 4:1-33, retrievd from http://aof.revues. org/index157.html, February 10, 2010.

Bonnain-Dulon, R. \& A. Brochot. (2004) De l'Authenticité des Produits Alimentaires. Ruralia, 14: 1-20, retrievd from http://ruralia.revues.org/969, February 10, 2010.

Douglas, M. (2008) Dechiphering a Meal. In C Counihan \&P V Esterik (eds.) Food and Culture. A Reader, pp.36-55. New York: Routledge.

Fischler, C. (1980) Food habits, social change and the nature/culture dilemma. Social Science Information, 19: 937-953.

Goody, J, (1996) Cooking, Cuisine and Class, Cambridge: Cambridge University Press.

Jousse, M. (1974) La Manducation de la parole, Paris: Editions Gallimard. Le Breton, D. (2009) Antropologia corpului şi modernitatea [Anthropology of the Body and Modernity]. Bucharest : Editura Cartier.

Matei C. (2009) Bucătarul de aur al Bucureştiului [Bucharest's Golden Chief], available at http://www.hrbexpert.ro/exclusiv_online/41/Bucatarul_de_aur_al_ Bucurestiului.html. (Consulted 11 March, 2010).

Mihailescu, V. , Iancu B. (2009) 'Produsele de calitate' şi patrimonializarea gustului în România [Quality products and taste patrimony in Romania]. Sociologie românească, 7 (3): 37 - 49.

Mintz S. W. and Du Bois C. M. (2002) The anthropology of food and eating. Annual Review of Anthropology, 31:99-119.

Muchnik, J., E. Biénabe \& C. Cerdan. (2005) Food Identity/food Quality: Insights from the 'Coalho' Cheese in the Northeast of Brazil. Anthropology of food, 4:1-42, retrievd from http://aof.revues.org/index110.html, February 10, 2010.

Mormont, M. (2009) Globalisations et écologisations des campagnes. Études rurales, $183: 143-160$, retrievd from http://www.cairn.info/article183, February 12, 2010.

Prigent-Simonin A. \& C. Hérault-Fournier. (2005) The role of trust in the perception of the quality of local food products: with particular reference to direct relationships between producer and consumer. Anthropology of food, 4:1-68, retrievd from http://aof.revues.org/index204.html, February 10, 2010.

Sylvestre, H. (2002) Agriculteurs, ruraux et citadins: les mutations des campagnes françaises, Dijon, CRDP de Bourgogne: Educagri.

Téchoueyres, I. \& V. Amilien. (2007) Produits locaux entre nature et culture : de la ferme voisine au terroir. Entretien avec Laurence Bérard. Anthropology of food, 4:1-50, retrievd from http://aof.revues.org/index108.html, February 10, 2010. Wilkinson, I. (2001) Anxiety in a risk society, London: Routledge. 
